\begin{tabular}{llr} 
Revista Psicologia, Saúde \& Doenças & ISSN 2182-8407 \\
Vol. 22, No. 3, 844-856, 2021 & www.sp-ps.pt \\
DoEnçAS & Sociedade Portuguesa de Psicologia da Saúde & https://doi.org/10.15309/21psd220306 \\
\hline
\end{tabular}

\title{
PSYCHOMETRIC PROPERTIES OF THE PARENTING DAILY HASSLES IN A SAMPLE OF PORTUGUESE PARENTS
}

\section{PROPRIEDADES PSICOMÉTRICAS DA PARENTING DAILY HASSLES NUMA AMOSTRA DE PAIS/MÃES PORTUGUESES}

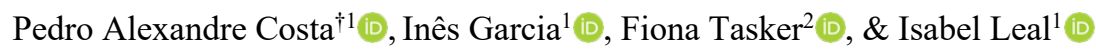 \\ ${ }^{1}$ William James Center for Research, ISPA - Instituto Universitário. Lisboa, Portugal, pcosta@ispa.pt, igarcia@ispa.pt, ileal@ispa.pt \\ ${ }^{2}$ Department of Psychological Sciences, Birkbeck, University of London, London, United Kingdom, f.tasker@bbk.ac.uk
}

\begin{abstract}
The Parenting Daily Hassles (PDH) scale is a screening measure of hassles associated with parenting. This study evaluated the psychometric properties of the PDH scale in a community sample of 444 Portuguese parents. Exploratory and confirmatory factor analyses provided evidence of factorial validity for both Intensity and Frequency dimensions. Internal reliability was high, although convergent validity was low. The associations between Frequency of PDH and satisfaction with life and dyadic adjustment provided evidence of convergent validity, and the associations between both Frequency and Intensity and psychological distress provided evidence of divergent validity. The findings provided further support for the adequacy and validity of the PDH scale, although the Intensity dimension performed slightly better than the Frequency dimension regarding factorial validity whereas the Frequency dimension performed better than the Intensity dimension regarding convergent and divergent validities. The PDH scale is a reliable measure of parenting daily stressors despite some limitations.
\end{abstract}

Keywords: Parenting Daily Hassles Scale; parenting stress; distress screening; factorial validity

Resumo: A escala Parenting Daily Hassles (PDH) é uma medida de triagem de incómodos associados à parentalidade. Este estudo avaliou as propriedades psicométricas da escala PDH numa amostra comunitária de 444 pais e mães portugueses. Análises fatoriais exploratórias e confirmatórias forneceram evidências de validade fatorial para as dimensões Intensidade e Frequência. A fiabilidade interna foi elevada embora a validade convergente tenha sido baixa. As associações entre a Frequência de PDH e a satisfação com a vida e ajustamento diádico evidenciaram validade convergente, e as associações entre ambas Frequência e Intensidade e o distress psicológico evidenciaram validade divergente. Os resultados forneceram suporte adicional para a adequação e validade da escala PDH, embora a Intensidade tenha tido um desempenho melhor quanto à validade de construto, e a Frequência um melhor desempenho quanto à validade convergente. A escala PDH foi considerada uma medida confiável de stressores parentais diários de parentalidade apesar de algumas limitações.

Palavras-Chave: Escala Parenting Daily Hassles; stress parental; triagem de distress; validade fatorial

Routine parenting stressors are a notable feature within families with young children, and may lead to distress in the parenting role (Crnic \& Low, 2002). Most parenting stressors, including managing

\footnotetext{
${ }^{\dagger}$ Morada de Correspondência: Rua Jardim do Tabaco, 34, 1149-041, Lisboa, Portugal. Email: pcosta@ispa.pt Submetido: 22 de julho de 2021

Aceite: 11 de outubro de 2021
} 
children's difficult behaviors, embody irregular and systemic distressing events that are not necessarily part of the family system but are significant to caregiving, and are not generally viewed as normative to family life (Crnic et al., 2005). 'Hassles' are daily stresses, defined as irritations in a parent's life, possibly chronic and continuous in time, and ranging from minor annoyances to major problems (Maybery \& Graham, 2001; Sarafino \& Ewing, 1999; Wijnberg \& Reding, 1999). Parenting Daily Hassles (PDH) are the day-to-day burdens of caring for children and its associated routines, which may include the challenges of attending to the nutritional needs of a picky toddler or ensuring that a child has clean clothes to wear for school every day (Crnic \& Low, 2002). According to Crnic and Greenberg (1990), PDH (distressful, disturbing incidents in daily life events) may lead to worries and difficulties in effective parenting, and may directly and indirectly affect children's outcomes. Though the individual normative PDH to child-care are likely to be inconsequential to parents, as the frequency or intensity becomes more pronounced, parents become increasingly likely to appraise their hassles as distressing (Crnic \& Low, 2002). Further, there is an increased risk of diminished parenting quality, less maternal positivity and dyadic pleasure during parent-child interactions, children's problem behaviors, and parental psychological distress (Barroso et al., 2018; Cook et al., 2017; Crnic et al., 2005; Stone et al., 2016).

Clinicians interested in assessing parenting routine stressors frequently use the PDH scale (e.g., Cock et al., 2017; Finegood et al., 2017). The PDH scale has been used to assess routine parenting hassles in various types of families from different backgrounds, namely, mothers of children with autism, mothers of children with behavioral problems, homeless mothers and fathers living in England, members of low-income urban Latino families or middle- to upper middle-class couples living in the Northwestern United States (Baker et al., 2000; Crnic \& Booth, 1991; Finegood et al., 2017; Quintero \& McIntyre, 2010; Tischler et al., 2004). Most importantly, the PDH scale is part of the Framework for the Assessment of Children in Need and their Families in England, which consists of a set of eight questionnaires aimed at early screening of children's emotional and behavioral problems, parents' difficulties, and overall family functioning (Department of Health, 2000; Department of Health et al., 2000), which "has been developed to provide a systematic way of analyzing, understanding and recording what is happening to children and young people within their families and the wider context of the community in which they live" (Gray, 2003, p. 4).

In the PDH scale, respondents are asked to rate how often they experience 20 hassles common to parenting children, as well as the degree to which they perceive each hassle as challenging (Crnic \& Greenberg, 1990). Composite scores from the Frequency scale represent the cumulative frequency of PDH experienced by respondents, while the Intensity scale represent the degree to which respondents view their lives as burdened by the day-to-day hassles of parenting children (Crnic \& Booth, 1991; Crnic \& Greenberg, 1990). According to the authors, the PDH scale assesses 'everyday parental stress' and not necessarily parental stress levels that may be considered pathological and can result in dysfunctional parenting (Crnic \& Low, 2002), for which the Parenting Stress Index (PSI; Abidin, 1990) may be more adequate. Studies have shown moderate positive correlations between the PDH scale and the PSI (e.g., Mazur, 2006). Therefore, the PDH scale can be a useful measure for early screening of parental difficulties in rearing their children. Although there is no normative cut-off point, the authors of the original scale suggest that a score above 50 on the Frequency dimension and above 70 on the Intensity dimension indicate a high frequency of hassling events and significant parental stress, respectively (Crnic \& Greenberg, 1990; Crnic \& Booth, 1991.

In the literature, there is a tendency to favor the PDH Intensity dimension over the Frequency dimension, due to a greater theoretical appraisal of severity over frequency ratings when assessing stressors (Crnic \& Low, 2002). In the original report on the PDH scale, Crnic and Greenberg (1990) suggested that scores on the Intensity scale exhibited more evidence of construct validity than scores on the Frequency scale. Intensity ratings are thought to measure the burden of routine parenting hassles better than frequency scales, since the cognitive appraisal of the stressful experience and it is impact is critical to the response. Despite its common use, the psychometric properties of the PDH 
scale have rarely been systematically examined. Crnic and Greenberg's (1990) initial study proposed two independent dimensions of parenting daily hassles: Frequency and Intensity. The authors conducted exploratory factor analyses and reported a high correlation between the two dimensions $(r$ $=0.78)$. The authors further reported high internal consistencies for both dimensions $(\alpha=0.81$ for Frequency and $\alpha=0.90$ for Intensity). However, except for the internal consistency and factorial validity, the authors examined only the Intensity dimension thoroughly. More recently, the structural validity of the PDH scale was examined but only considering the Intensity dimension as well (Taylor, 2019). Both studies provided some evidence of convergent validity insofar as the PDH Intensity scale correlated significantly with marital satisfaction, satisfaction with parenting, family relationships and life stress (Crnic \& Greenberg, 1990; Taylor, 2019).

The PDH scale has been used in different countries outside the US (e.g., China, Korea, the Netherlands) and translated into different languages (e.g., Mandarin, Korean, Dutch) using the scale's original two dimensions. However, no study has reported performing any factorial analyses or made reference to psychometric studies prior to using the scale (Cheah et al., 2016; Chen \& Luster, 2002; Ostberg et al., 2007). Further, Crnic and Greenberg's (1990) study reported weak correlations between PDH and life satisfaction, and weak to moderate correlations between marital satisfaction and PDH have also been reported (Stoneman \& Gavidia-Payne, 2006; Taylor, 2018). To our knowledge, no study to date has examined the factorial and construct validity of both dimensions of the PDH scale after the initial analysis by the authors who created the scale. As such, the purpose of this study was to examine the reliability, factorial and construct validities of the PHS scale.

\section{METHODS}

\section{Participants}

A total of 444 questionnaires were completed by parents, either the father $(30 \%)$ or the mother $(70 \%)$ in each family. Parents' ages ranged from 23 to 65 years $(M=42 ; S D=5)$. About $80 \%$ reported being in a legally recognized relationship (marriage or civil union), and only about $12 \%$ reported not being in a relationship with the co-parent at the time of the study. Most parents reported having completed college, being currently employed, living in an urban location, and a medium to high annual income. The total number of children per family ranged from one to six, with an average and mode of two. Finally, the number of people in the family ranged from one to eight, with an average and mode of four people (Table 1).

\section{Measures}

All participants provided information about themselves and their co-parents (e.g., age, gender, education, occupation) and their relationship (e.g., duration of and satisfaction with their relationship). Participants also completed measures of dyadic adjustment, global cognitive judgments of satisfaction with one's life, general psychological distress, and the Portuguese version of the PDH Scale. 
Table 1. Sample main sociodemographic information

\begin{tabular}{lcc}
\hline & $\boldsymbol{n}$ & $\mathbf{( \% )}$ \\
\hline Relationship * & 305 & 68.7 \\
Married & 50 & 11.4 \\
Civil union & 34 & 7.7 \\
In a relationship & 20 & 4.5 \\
Single & 34 & 7.7 \\
Divorced/Separated & & \\
Place of residence & 185 & 41.7 \\
Urban / Big city & 130 & 29.3 \\
Urban outskirts & 60 & 13.5 \\
Semiurban/Small town & 68 & 15.3 \\
Village / Rural & & 18.7 \\
Level of education & 83 & 81.3 \\
High school or less & 361 & 87.4 \\
College degree & & 2.3 \\
Professional status & 387 & 7.4 \\
Employed & 10 & 3.1 \\
Self-employed & 33 & \\
Unemployed & 14 & 5.9 \\
Retired & & 23.0 \\
Yearly income & & 35.1 \\
$€ 7.000$ or less & 26 & 25.9 \\
$€ 7.001$ to $€ 20.000$ & 102 & 6.5 \\
$€ 20.001$ to $€ 40.000$ & 156 & 115 \\
$€ 40.001$ to $€ 80.000$ & 29 & \\
More than $€ 80.000$ & & \\
\hline
\end{tabular}

Note 1: *Although some parents reported not being in a relationship at the moment, all participants reported sharing their children's coparenting.

Note 2: When percentages do not add up to 100 , it is due to missing values.

PDH scale. Crnic and Greenberg (1990) and Crnic and Booth (1991) developed a scale that aimed to assess the frequency and intensity of 20 potential parenting daily hassles experienced by adults caring for children. The questionnaire can be completed by parents or caretakers of young children, who are asked to answer how often in the past six months each of the 20 events occurred, measured in a 4-point Likert scale ranging from 1 (Rarely) to 4 (Constantly), and quantify each hassle in a 5point Likert scale ranging from 1 (No hassle) to 5 (Big hassle). A final score for each dimension was calculated from the mean values, in which higher scores reflected higher frequency and higher intensity of parenting daily hassles.

The PDH scale translation was developed using the latest ITC Guidelines for Translation and Adapting Tests (International Test Commission [ITC], 2017), through a double-translation and reconciliation procedure. Two bilingual researchers translated the PDH original scale from English to Portuguese, and a third researcher, fluent in both Portuguese and English, helped to reconcile any discrepancies and reconcile them into one final version. The final version was further examined regarding its items' cultural sensitivity and slight changes to the wording of some of the items were made accordingly. Item order, scale presentation, and response format was kept the same as the original.

Revised Dyadic Adjustment Scale (RDAS). Busby et al. (1995) proposed a revised and shorter version of the original Dyadic Adjustment Scale (32 items; Spanier, 1976) for the purpose of assessing dyadic adjustment. RDAS is composed by 14 items measured in a 6-point Likert-scale. The scale comprises three dimensions: Consensus (6 items), Satisfaction (4 items), and Cohesion (4 items). There is psychometric evidence demonstrating the applicability of RDAS in different cultures, 
namely in Portugal (Costa et al.; Dinkel \& Balck, 2006). Only the Satisfaction subscale $(\alpha=0.81)$ was used in this study for being more likely to provide convergent validity with the PDH scale (e.g., Rollè et al., 2017). A final score was calculated from the mean values, and the items were recoded so that higher scores reflected greater dyadic satisfaction.

Satisfaction With Life Scale (SWLS). The SWLS scale is a 5-item scale developed by Diener et al. (1985), and adapted to Portugal by Simões (1992). It assesses a person's degree of satisfaction with their living conditions, choices, and what they have achieved. The scale uses a 7-point Likert scale, ranging from 1 (Strongly disagree) to 7 (Strongly agree). Internal consistency for this study was high $(\alpha=0.88)$. A final score was calculated from the mean values, in which higher scores reflected greater satisfaction with life.

Kessler's Psychological Distress Scale (K6). K6 is a short form of the Kessler Psychological Distress Scale and is widely used for measuring general psychological distress (Kessler et al., 2002). It has been translated and adapted to Portugal (Pereira et al., 2019). The K6 items are answered in a 5-point Likert scale, ranging from 1 (None of the time) to 5 (All the time), to measure whether the individual felt distressed during the last 30 days (Kessler et al., 2002). Internal consistency for this study was high $(\alpha=0.88)$. A final score was calculated from the mean values, in which higher scores reflected greater psychological distress.

\section{Procedures}

Ethical approval was obtained from the University's Ethics Committee. An intentional nonprobabilistic sampling method was used to recruit study participants to take part in an online survey. Parents were recruited through contacts with schools and parents' associations in Portugal, and were sent an email describing the study aims, and instructions on how to participate in the study. Contact details of the lead researcher (first author) were also provided to clarify any question about the study. The questionnaire was hosted on an online survey platform. All participants had the opportunity to clarify questions about the study aims and/or procedures by e-mail, and anonymity and confidentiality were guaranteed throughout the study. No compensation was offered to participants. Informed consent was obtained from all participants in this study. Data was collected between January and June 2016.

\section{Statistical Analyses}

Missing values were imputed for variables where its frequency was lower than $10 \%$., using the mean interpolation method. Items sensitivity was assessed through skewness (Sk) and kurtosis (K), with absolute values lower than three and seven, respectively, indicating the absence of a severe violation of the normality assumption (Kline, 2015). One-factor models for PDH were tested through Exploratory Factor Analysis (EAF) separately for each dimension; Frequency and Intensity, followed by Confirmatory Factor Analysis (CFA). The overall fit of the models was assessed using Chi-Square $(\chi 2 / d f)$, Comparative Fit Index (CFI), Goodness of Fit Index (GFI), and Root Mean Square Error of Approximation (RMSEA). Values above 0.90 on the CFI and the GFI, and below 0.10 on the RMSEA are indicators of an acceptable model fit. Values above 0.95 on the CFI and the GFI, and below 0.05 on the RMSEA are indicators of good model fit (Hair et al., 2006).

Cronbach's alpha $(\alpha)$ and Composite Reliability (CR) scores were calculated to assess the measure's internal reliability (Fornell \& Larcker, 1981; Hair et al., 2009). Cronbach's alpha and CR were considered to have acceptable to good reliability if they were higher than 0.70 and 0.80 , respectively. Convergent validity was evaluated by calculating the Average Variance Extracted (AVE), considered adequate if higher than 0.50 (Hair et al., 2009). Convergent and divergent validities were explored by computing Pearson correlation coefficients between PDH scale and criterion measures (Cohen, 
1988). All statistical analyses were performed using software IBM SPSS Statistics and AMOS (v. 25, IBM Corp., Armonk, NY).

\section{RESULTS}

\section{Descriptive Statistics}

Descriptive statistics indicated that the entire Likert-scale was used for all items, with answers ranging from 1 to 4 for all 20 items in the Frequency dimension, and from 1 to 5 in the Intensity dimension (Table 2). Univariate normality was analyzed through skewness and kurtosis values, indicating no significant violations of the normality assumption, except for item 19 ("The kids have difficulties with friends") of the Frequency dimension, that showed both skewness and kurtosis problems, and item 14 ("The kids get dirty several times a day requiring changes of clothing") of the Intensity dimension, that showed a marginally high kurtosis value. The average scores for PDH items ranged from $1.29(S D=.66)$ to $2.58(S D=.87)$ for the Frequency dimension and from $1.37(S D=$ $.67)$ to $3.01(S D=1.13)$ for the Intensity dimension.

Table 2. Descriptive statistics for PDH items

\begin{tabular}{lcccc|cccc}
\hline & \multicolumn{3}{c}{ Frequency dimension } & \multicolumn{4}{c}{ Intensity dimension } \\
& $M$ & $S D$ & $|\mathrm{Sk}|$ & $|\mathrm{K}|$ & $M$ & $S D$ & $|\mathrm{Sk}|$ & $|\mathrm{K}|$ \\
\hline Item 1. Kids' messes & 2.58 & 0.87 & 0.05 & 0.69 & 3.01 & 1.13 & 0.17 & 0.62 \\
Item 2. Kids' complains & 2.05 & 0.88 & 0.49 & 0.52 & 2.62 & 1.26 & 0.25 & 0.99 \\
Item 3. Picky eating & 1.90 & 0.96 & 0.77 & 0.47 & 2.48 & 1.30 & 0.37 & 0.98 \\
Item 4. Kids' don't listen & 1.96 & 0.87 & 0.57 & 0.43 & 2.77 & 1.31 & 0.04 & 1.16 \\
Item 5. Finding baby-sitters & 1.35 & 0.81 & 2.32 & 4.28 & 1.87 & 0.73 & 2.31 & 6.96 \\
Item 6. Kids' schedules & 1.80 & 0.93 & 0.95 & 0.05 & 1.95 & 1.08 & 1.12 & 0.60 \\
Item 7. Siblings' arguments & 2.09 & 0.95 & 0.44 & 0.78 & 2.78 & 1.21 & 0.22 & 0.64 \\
Item 8. Entertain kids & 2.02 & 0.83 & 0.47 & 0.35 & 1.60 & 0.81 & 1.58 & 2.55 \\
Item 9. Struggles over bedtime & 2.17 & 0.97 & 0.37 & 0.88 & 2.43 & 1.24 & 0.48 & 0.80 \\
Item 10. Interfering with chores & 1.38 & 0.62 & 1.58 & 2.09 & 1.65 & 0.92 & 1.48 & 1.55 \\
Item 11. Constant monitoring & 1.92 & 0.89 & 0.70 & 0.28 & 1.71 & 0.94 & 1.41 & 1.60 \\
Item 12. Interrupting adults & 2.11 & 0.83 & 0.44 & 0.29 & 2.74 & 1.25 & 0.05 & 1.03 \\
Item 13. Changing plans & 2.20 & 0.88 & 0.33 & 0.60 & 1.77 & 0.97 & 1.22 & 0.86 \\
Item 14. Clothes changing & 1.29 & 0.66 & 2.47 & 5.67 & 1.37 & 0.67 & 2.61 & 7.35 \\
Item 15. Getting privacy & 1.88 & 0.99 & 0.89 & 0.31 & 1.68 & 1.00 & 1.61 & 2.03 \\
Item 16. Behavior in public & 1.30 & 0.59 & 2.17 & 4.99 & 1.89 & 1.17 & 1.28 & 0.69 \\
Item 17. Getting ready & 1.88 & 0.84 & 0.62 & 0.39 & 2.37 & 1.24 & 0.50 & 0.78 \\
Item 18. Finding day care & 1.61 & 0.84 & 1.29 & 0.85 & 1.77 & 1.08 & 1.46 & 1.30 \\
Item 19. Difficulties with friends & 1.17 & 0.48 & 3.00 & 10.1 & 1.72 & 1.12 & 1.78 & 2.23 \\
Item 20. Run extra errands & 1.88 & 0.86 & 0.76 & 0.09 & 1.70 & 0.94 & 1.44 & 1.53 \\
\hline
\end{tabular}




\section{Factorial Validity}

Exploratory Factor Analyses. Before testing the EFA for the Frequency and Intensity dimensions of the PDH, item 5 ("Baby-sitters are hard to find") and item 7 ("Sibling arguments or fights require a 'referee"') were eliminated because most parents reported not using baby-sitters and over a quarter of the parents had only one child. The analyses were conducted with the remaining 18 items. The results of the EFA for the Frequency dimension suggested that one factor explained $24 \%$ of the variance. The Kaiser-Meyer-Olkin Measure of Sampling Adequacy was 0.826, indicating that the sample was adequate, and Bartlett's Test of Sphericity gave a p-value of $<0.001$. A Scree plot of the eigenvalues strongly suggested a one-factor structure. As shown in Table 3, items 6, 14, and 19 had factorial weights below 0.30 and were not significantly associated with the remaining items, indicating that these items may not adequately reflect the latent variable.

The results of the EFA for the Intensity dimension suggested that one factor explained $32 \%$ of the variance. The Kaiser-Meyer-Olkin Measure of Sampling Adequacy was 0.867, indicating that the sample was adequate, and Bartlett's Test of Sphericity gave a p-value of $<0.001$. A Scree plot of the eigenvalues strongly suggested a one-factor structure. All individual factorial weights were above 0.40 , thus supporting the inclusion of all items. Given that the EAF of the Frequency dimension supported the exclusion of three items whereas the EAF of the Intensity dimension supported the inclusion of all items, no items were excluded prior to conducting the CFAs in order to examine whether some items should in fact be excluded.

Table 3. Factor loadings from the EFA of the PDH

\begin{tabular}{lc|c}
\hline & Frequency scale & Intensity scale \\
\hline & $\beta$ & $\beta$ \\
Item 1 & 0.50 & 0.42 \\
Item 2 & 0.64 & 0.57 \\
Item 3 & 0.54 & 0.58 \\
Item 4 & 0.59 & 0.60 \\
Item 6 & 0.29 & 0.45 \\
Item 8 & 0.45 & 0.67 \\
Item 9 & 0.46 & 0.56 \\
Item 10 & 0.56 & 0.66 \\
Item 11 & 0.60 & 0.66 \\
Item 12 & 0.60 & 0.48 \\
Item 13 & 0.51 & 0.52 \\
Item 14 & 0.23 & 0.62 \\
Item 15 & 0.51 & 0.54 \\
Item 16 & 0.50 & 0.64 \\
Item 17 & 0.54 & 0.55 \\
Item 18 & 0.39 & 0.46 \\
Item 19 & 0.20 & 0.57 \\
Item 20 & 0.48 & 0.63 \\
\hline
\end{tabular}

Confirmatory Factor Analyses. Baseline models were tested with the 18 items. For the Frequency dimension, the four combined fit indices did not confirm an acceptable model fit, $\chi 2 / \mathrm{df}=2.771$; CFI $=0.796 ; \mathrm{GFI}=0.907 ; \mathrm{RMSEA}=0.063$, C.I.90\% $[0.056 ; 0.125]$. The modification indices indicated 
significant correlations between the errors of items 6 and 13, 13 and 20, and 8 and 11. After inserting these correlations, the fitness of the one-factor model significantly improved, $\chi^{2} / d f=2.234$; $\mathrm{CFI}=$ 0.861 ; GFI $=0.928$; RMSEA $=0.053$, C.I.90\% [0.045; 0.061]. As shown in Table 4, factor loadings were all statistically significant with standardized values exceeding 0.30 , except for items $6,14,18$ and 19, which had slightly lower values. Multivariate normality was confirmed for all items except for item 19.

For the Intensity dimension, the four combined fit indices did not confirm an acceptable model fit, $\chi 2 / \mathrm{df}=4.095 ; \mathrm{CFI}=0.777 ; \mathrm{GFI}=0.863 ;$ RMSEA $=0.084$, C.I.90\% $=[0.076 ; 0.091]$. The modification indices indicated significant correlations between the errors of items 3 and 4, 16 and 19, 2 and 3, 2 and 4, and 8 and 17. After inserting these correlations, the fitness of the one-factor model significantly improved, $\chi^{2} / d f=3.211 ; \mathrm{CFI}=0.847$; GFI $=0.899 ; \mathrm{RMSEA}=0.071$, C.I. $90 \%=[0.063$; 0.078]. Factor loadings were all statistically significant with standardized values exceeding 0.40 . Multivariate normality was confirmed for all items except for item 14.

Table 4. Factor loadings from the CFA of the PDH

\begin{tabular}{lc|c}
\hline & Frequency dimension & Intensity dimension \\
\hline Item 1. & $\beta$ & $\beta$ \\
Item 2. & 0.46 & 0.40 \\
Item 3. & 0.61 & 0.48 \\
Item 4. & 0.47 & 0.43 \\
Item 6. & 0.56 & 0.49 \\
Item 8. & 0.24 & 0.45 \\
Item 9. & 0.35 & 0.53 \\
Item 10. & 0.57 \\
Item 11. & 0.41 & 0.70 \\
Item 12. & 0.50 & 0.64 \\
Item 13. & 0.49 & 0.48 \\
Item 14. & 0.54 & 0.49 \\
Item 15. & 0.41 & 0.42 \\
Item 16. & 0.24 & 0.48 \\
Item 17. & 0.41 & 0.46 \\
Item 18. & 0.46 & 0.58 \\
Item 19. & 0.44 & 0.44 \\
Item 20. & 0.27 & 0.41 \\
\hline Ite: All $p<001$ & 0.51 \\
\hline
\end{tabular}

Note: All $p$ 's $<0.001$

\section{Reliability and Construct Validity}

For the Frequency dimension, internal consistency was good $(\alpha=0.79)$ as was composite reliability $(\mathrm{CR}=0.79)$. Convergent validity was low $(\mathrm{AVE}=0.18)$. For the Intensity dimension, internal consistency was good $(\alpha=0.85)$ as was composite reliability $(\mathrm{CR}=0.86)$, both higher than those for the Frequency dimension. However, low convergent validity was observed (AVE $=0.25$ ). The correlation between the Frequency and Intensity dimensions was high $(p=0.65, p<0.001)$.

For the Frequency dimension, total scores ranged from 20 to $59(M=33.55 ; S D=7.37)$, from a possible range adjusted for 18 items of 18-72. For the Intensity dimension total scores ranged from 18 and $72(M=36.96 ; S D=11.40)$ from a possible range adjusted for 18 items of $18-90$. In this 
sample, the mean values for each dimension were well under the scores that indicate potential problems, with only $9 \%$ of the parents reporting a high frequency of hassling events and $4 \%$ reporting significant parenting stress.

Bivariate correlations between the Frequency and the Intensity dimensions of the PDH scale and the criterion variables satisfaction with life, psychological distress, and dyadic satisfaction were calculated (Table 5). Convergent validity was assessed through the correlations between the Frequency and Intensity dimensions of the PDH scale and psychological distress; Divergent validity was assessed through the correlations between the Frequency and Intensity dimensions and satisfaction with life and dyadic satisfaction. Some support for the convergent validity was found in the weak but significant correlations between Frequency and psychological distress, evidence of divergent validity in the weak but significant correlations between Frequency and satisfaction with life, dyadic satisfaction. Some support for the convergent validity was supported by the weak but significant correlation between Intensity and psychological distress, but no evidence of divergent validity for the Intensity was found.

Table 5. Convergent and divergent validities between PDH scale and criterion measures.

\begin{tabular}{lc|c}
\hline $\begin{array}{l}\text { Convergent validity } \\
\text { Psychological distress }\end{array}$ & Frequency dimension & Intensity dimension \\
\hline $\begin{array}{l}\text { Divergent validity } \\
\text { Satisfaction with life }\end{array}$ & $0.31^{*}$ & $0.26^{*}$ \\
Dyadic satisfaction & $-0.19^{*}$ & -0.10 \\
\hline
\end{tabular}

Note: $* p<.001$

\section{DISCUSSION}

The PDH scale is commonly used to assess parenting events that may be distressing for parents, particularly those with young children. According to the authors who created the PDH scale, these hassles are viewed as frustrating and irritating demands related to parenting that, due to the frequency and intensity at which they occur, may cause parenting stress, and thus affect parents' and families' well-being. These hassles have been receiving increasing interest in recent years due to their potential to negatively affect the family, and directly and indirectly affect the behavior of children (e.g., Finegood et al., 2017). However, few studies have assessed the PDH scale's psychometric properties, after the initial development studies in the early 1990s. Given that parenting is context-dependent, psychometric studies are needed. Thus, this study aimed to examine the psychometric properties of the PDH scale and contribute to its adaptation to the Portuguese context.

The findings from this study provided further support for the reliability, factorial and construct validities of the PDH scale. Both exploratory and confirmatory factor analyses supported a one-factor structure for the frequency and intensity dimensions, although some changes to the original structure were done. One limitation was that two items had to be deleted prior to the factorial analyses due to the sample's characteristics: item 5 mentioned using babysitters, which was not prevalent among the participants; item 7 was deleted because a significant number of participants reported having a single child. In fact, having a single child has increased in recent years in Portugal, with an average of 1.4 children per family in 2018 (Pordata, 2020). Across the European Union, the average number of children per family is also under 2 (Pordata, 2020). The evidence suggests that the two items may be excluded from the scale when collecting data from community samples without compromising the scale's adequacy. 
The factorial analyses indicated the need to correlate several pairs of items' errors to adjust the model to the data. Although the addition of error term correlations is somewhat usual in psychometric studies, it constitutes a limitation, as these correlations suggest item variance that is not attributable to the item itself. However, because the correlations between items' errors were not the same for the Frequency and Intensity dimensions, they may also be attributable to other factors than a pattern of common error variance between items. For the Frequency dimension, the three correlations included seem to be random, and possibly specific to this sample, although some common variance may relate to the interference of children's activities on other household tasks (e.g., items 6 and 13). For the Intensity dimension, the common thread among items 2, 3, and 4 is children's behaviors of 'nagging' and complaining, suggesting that parents may not dissociate the contexts where these behaviors happen in terms of the hassle that the 'nagging' provokes. Nevertheless, future studies are needed to corroborate these assumptions.

In addition, a few items from the Frequency dimension, but not from the Intensity dimension, had factor loadings below the .3 threshold on both exploratory and confirmatory analyses, suggesting limited contribution of these items to the assessment of its latent variable. This was the case of items 6,14 , and 19. Because no common thread between these items could be determined, this finding may not necessarily be corroborated in other studies. In fact, the three items were among the items with the lowest mean values in the Frequency dimension. Moreover, most items in the Frequency dimensions had low to moderate factor loadings. We argue that this may be acceptable if we consider that the PDH Frequency dimension is more of an inventory of events, which may or may not happen in each family, than a measure of a latent construct (parenting hassles/stress). As the authors of the original version propose, the Intensity dimension is a more reliable measure of parenting stress, as it more accurately reflects a parent's cognitive appraisal of daily hassles and the impact they have on family well-being. Regarding internal reliability, the scale presented good Cronbach's alphas and composite reliability for both dimensions ( $\alpha=0.79$ for frequency, and $\alpha=0.85$ for intensity), which are similar to those reported in the original study and others (e.g., Gülseven et al., 2018; Rutgers et al., 2007). Nevertheless, a relatively small percentage of the variance was explained by each dimension of the PDH individually $(<0.40)$, suggesting that the PDH scale may need to be reviewed and updated in order to account for potentially newer or more common hassles associated with parenting children in this millennium as the scale remains the same since its creation in the 1990s.

Taken together, the current findings suggest that the Intensity dimension performed slightly better than the Frequency dimension regarding its factorial validity, which is expected, given that the Intensity dimension is a more accurate measure of potential parenting stress. These findings provide further evidence of the PDH scale construct validity, in spite of the aforementioned limitations. In contrast, the Frequency dimension provided some evidence of both convergent and divergent validities to a greater extent than the Intensity dimension. As such, the higher the frequency of potentially hassling events the lower the parents' satisfaction with life and the couple's relationship adjustment, and the higher the parents' general distress. These findings are in line with previous psychometric studies of the PDH scale, which have reported comparable correlations between parenting daily hassles and satisfaction with life and marital satisfaction (Crnic \& Greenberg, 1990; Taylor, 2019). However, for the intensity dimension, only evidence of convergent validity was found in the significant correlation between the intensity of parenting hassles and parent's general psychological distress, indicating that the higher the intensity of parenting daily hassles the higher the parents' psychological distress. The lack of significant associations between the Intensity of parenting daily hassles and satisfaction with life and dyadic adjustment was unexpected given previous evidence; It is known that parenting stress negatively impacts the quality of relationships within the family (e.g., Crnic \& Booth, 1991; Crnic \& Greenberg, 1990; Rollè et al., 2017) and we can speculate that the lack of associations may be due to the overall low levels of parenting daily hassles reported by the parents in this study. 


\section{Limitations}

This study had some limitations that should be acknowledged. The first limitation regards the fact that this research used non-random online sampling, and some characteristics of the Portuguese parents (e.g., $81 \%$ of the sample had a college degree), may compromise the generalizability of the results of the study. Regarding the methodology, the present study only examined the factorial validity, internal consistency, and construct validity of the PDH scale, and future studies should also evaluate test-retest reliability and predictive validity. Future studies should also further examine the psychometric properties of the PDH scale using both community and clinical samples. The limitations found regarding the low factorial weights of some of the items from the frequency dimension, the existence of common variance between some items, and low convergent validity of both dimensions may be attributable to the use of community samples to some extent. Psychometric studies with clinical samples, namely, parents with children with behavior problems or chronic illness, may be useful to provide a greater insight into the scale's adequacy in screening for parental stress.

\section{FUNDING}

Este trabalho foi apoiado pela Fundação para a Ciência e a Tecnologia através de uma bolsa individual com a referência SFRH/BPD/99752/2014, atribuída ao primeiro autor.

\section{REFERENCES}

Abidin, R. R. (1990). Parenting Stress Index (PSI) manual ( $3^{\text {rd }}$ edition). Pediatric Psychology Press.

Baker, B. L., Heller, T. L., \& Henker, B. (2000). Expressed emotion, parenting stress, and adjustment in mothers of young children with behavior problems. Journal of Child Psychology and Psychiatry and Allied Disciplines, 41, 907-915. https://doi.org/10.1111/1469-7610.00678

Barroso, N. E., Mendez, L., Graziano, P. A., \& Bagner, D. M. (2018). Parenting stress through the lens of different clinical groups: A systematic review and meta-analysis. Journal of Abnormal Child Psychology, 46, 449-461. https://doi.org/10.1007/s10802-017-0313-6

Busby, D. M., Christensen, C., Crane, D. R., \& Larson, J. (1995). A revision of the dyadic adjustment scale for use with distressed and nondistressed couples: Construct hierarchy and multidimensional scales. Journal of Marital and Family Therapy, 21, 289-308. https://doi.org/10.1111/j.17520606.1995.tb00163.x

Cheah, C.S., Yu, J., Hart, C.H., Özdemir, S.B., Sun, S., Zhou, N., Olsen, J.A., \& Sunohara, M. (2016). Parenting hassles mediate predictors of Chinese and Korean immigrants' psychologically controlling parenting. Journal of Applied Developmental Psychology, 47, 13-22. https://doi.org/10.1016/j.appdev.2016.09.005

Chen, F., \& Luster, T. (2002). Factors related to parenting practices in Taiwan. Early Child Development and Care, 172, 413-430. https://doi.org/10.1080/0300443022000034942

Cock, E. S. A., Henrichs, J., Klimstra, T. A., Maas, A. J. B. M., Vreeswijk, C. M. J. M., Meeus, W. H. J., \& van Bakel, H. J. A. (2017). Longitudinal associations between parental bonding, parenting stress, and executive functioning in toddlerhood. Journal of Child and Family Studies, 26, 17231733. https://doi.org/10.1007/s10826-017-0679-7

Costa, P. A., Pereira, H., \& Leal, I. (2011). Desenvolvimento da escala revista de ajustamento diádico (RDAS) com casais do mesmo sexo. Actas do VIII Congresso Iberoamericano de Avaliação/Evaluación Psicológica 
Crnic, K. A., \& Booth, C. L. (1991). Mothers' and fathers' perceptions of daily hassles of parenting across early childhood. Journal of Marriage and Family, 53, 1042-1050. https://doi.org/10.2307/353007

Crnic, K. A., Gaze, C., \& Hoffman, C. (2005). Cumulative parenting stress across the preschool period: Relations to maternal parenting and child behaviour at age 5. Infant and Child Development, 14, 117-132. https://doi.org/10.1002/icd.384

Crnic, K. A., \& Greenberg, M. T. (1990). Minor parenting stresses with young children. Child Development, 61, 1628-1637. https://doi.org/10.1111/j.1467-8624.1990.tb02889.x

Crnic, K. A., \& Low, C. (2002). Everyday stresses and parenting. In M. H. Bornstein (Ed.), Handbook of parenting: Practical issues in parenting (2nd ed., Vol. 5, pp. 243-267). Lawrence Erlbaum Associates.

Department of Health (2000). Assessing children in need and their families: Practice guidance. The Stationery Office.

Department of Health, Cox, A. \& Bentovim, A. (2000). The family assessment pack of questionnaires and scales. The Stationery Office.

Diener, E., Emmons, R. A., Larsen, R. J., \& Griffin, S. (1985). The Satisfaction With Life Scale. Journal of Personality Assessment, 49, 71-75. https://doi.org/10.1207/s15327752jpa4901_13

Dinkel, A., \& Balck, F. (2006). Psychometric analysis of the German Dyadic Adjustment Scale. Zeitschrift fur Psychologie, 214, 1-9.

Finegood, E. D., Raver, C. C., DeJoseph, M. L., \& Blair, C. (2017). Parenting in poverty: Attention bias and anxiety interact to predict parents' perceptions of daily parenting hassles. Journal of Family Psychology, 31, 51-60. https://doi.org/10.1037/fam0000291

Fornell, C., \& Larcker, D. F. (1981). Evaluating structural equation models with unobservable variables and measurement error. Journal of Marketing Research, 18, 39-50. https://doi.org/10.2307/3151312

Gray, P. H., Edwards, D. M., O'Callaghan, M. J., \& Cuskelly, M. (2012). Parenting stress in mothers of preterm infants during early infancy. Early Human Development, 88, 45-49. https://doi.org/10.1016/j.earlhumdev.2011.06.014

Gülseven, Z., Carlo, G., Streit, C., Kumru, A., Selçuk, B., \& Sayıl, M. (2018). Longitudinal relations among parenting daily hassles, child rearing, and prosocial and aggressive behaviors in Turkish children. Social Development, 27, 45-57. https://doi.org/10.1111/sode.12247

Hair, J. F., Black, W. C., Babin, B. J., \& Anderson, R. E. (2009). Multivariate data analysis (7th ed.). Prentice Hall.

International Test Commission (2017). The ITC guidelines for translating and adapting tests (2nd edition). Retrieved from www.InTestCom.org

Kessler, R. C., Andrews, G., Colpe, L. J., Hiripi, E., Mroczek, D. K., Normand, S. L., Walters, E. E., \& Zaslavsky, A. M. (2002). Short screening scales to monitor population prevalences and trends in non-specific psychological distress. Psychological Medicine, 32, 959-976. https://doi.org/10.1017/s0033291702006074

Kline, R. B. (2015). Principles and practice of structural equation modeling. (4th ed.). Guilford Press.

Maybery, D. J., \& Graham, D. (2001). Hassles and uplifts: Including interpersonal events. Journal of the International Society for the Investigation of Stress, 17, 91-104. https://doi.org/10.1002/smi.891

Mazur, E. (2006). Biased appraisals of parenting daily hassles among mothers of young children: Predictors of parenting adjustment. Cognitive Therapy and Research, 30, 161-175. https://doi.org/10.1007/s10608-006-9031-z

Ostberg, M., Hagekull, B., \& Hagelin, E. (2007). Stability and prediction of parenting stress. Infant and Child Development, 16, 207-223. https://doi.org/10.1002/icd.516 
Pavot, W., \& Diener, E. (2008). The Satisfaction with Life Scale and the emerging construct of life satisfaction. Journal of Positive Psychology, 3, 137-152. https://doi.org/10.1080/17439760701756946

Pereira, A., Oliveira, C. A., Bártolo, A., Monteiro, S., Vagos, P., \& Jardim, J. (2019). Reliability and factor structure of the 10-item Kessler Psychological Distress Scale (K10) among Portuguese adults. Ciencia \& Saúde Coletiva, 24, 729-736. https://doi.org/10.1590/141381232018243.06322017

Quintero, N., \& McIntyre, L. L. (2010). Sibling adjustment and maternal well-being: An examination of families with and without a child with an autism spectrum disorder. Focus on Autism and other Developmental Disabilities, 25, 37-46. https://doi.org/10.1177/1088357609350367

Rollè, L., Prino, L. E., Sechi, C., Vismara, L., Neri, E., Polizzi, C., Trovato, A., Volpi, B., Molgora, S., Fenaroli, V., Ierardi, E., Ferro, V., Lucarelli, L., Agostini, F., Tambelli, R., Saita, E., Riva Crugnola, C., \& Brustia, P. (2017). Parenting stress, mental health, dyadic adjustment: A structural equation model. Frontiers in Psychology, 8, 839. https://doi.org/10.3389/fpsyg.2017.00839

Rutgers, A. H., van Ijzendoorn, M. H., Bakermans-Kranenburg, M. J., Swinkels, S. H., van Daalen, E., Dietz, C., Naber, F. B., Buitelaar, J. K., \& van Engeland, H. (2007). Autism, attachment and parenting: A comparison of children with autism spectrum disorder, mental retardation, language disorder, and non-clinical children. Journal of Abnormal Child Psychology, 35, 859-870. https://doi.org/10.1007/s10802-007-9139-y

Sarafino, E. P., \& Ewing, M. (1999). The Hassles Assessment Scale for students in college: Measuring the frequency and unpleasantness of and dwelling on stressful events. Journal of American College Health, 48, 75-83. https://doi.org/10.1080/07448489909595677

Simões, A. (1992). Ulterior validação de uma escala de satisfação com a vida (SWLS). Revista Portuguesa de Pedagogia, 26, 503-515.

Spanier, G. B. (1976). Measuring dyadic adjustment: New scales for assessing the quality of marriage and similar dyads. Journal of Marriage and Family, 38, 15-28. https://doi.org/10.2307/350547

Stone, L. L., Mares, S. H. W., Otten, R., Engels, R. C. M. E., \& Janssens, J. M. A. M. (2016). The co-development of parenting stress and childhood internalizing and externalizing problems. Journal of Psychopathology and Behavioral Assessment, 38, 76-86. https://doi.org/10.1007/s10862-015-9500-3

Taylor, J. (2019). Structual validity of the Parenting Daily Hassles Intensity Scale. Stress and Health, 35, 176-186. https://doi.org/10.1002/smi.2852

Tischler, V., Karim, K., Rustall, S., Gregory, P., \& Vostanis, P. (2004). A family support service for homeless children and parents: Users' perspectives and characteristics. Health \& Social Care in the Community, 12, 327-335. https://doi.org/10.1111/j.1365-2524.2004.00502.x

Wijnberg, M. H., \& Reding, K. M. (1999). Reclaiming a stress focus: The hassles of rural, poor single mothers. Families in Society, 80, 506-515. https://doi.org/10.1606/1044-3894.1480 